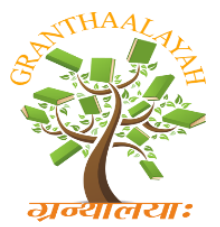

\author{
INTERNATIONAL JOURNAL OF RESEARCH - \\ GRANTHAALAYAH \\ A knowledge Repository
}

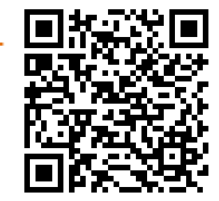

\title{
STUDY OF VARIOUS FIVE EXTRACTS OF TRACHYSPERMUM AMMI SEEDS ON SELECTED FOUR GRAM-NEGATIVE COOKED FOOD SPOILAGE BACTERIAL STRAINS BY DISK DIFFUSION METHOD
}

\author{
Usha Masih
}

Department of Botany, M. J. B. Govt. P. G. Girls College, Indore, M.P, India

\begin{abstract}
Bacterial foodborne diseases are caused by consumption of foods contaminated with bacteria or their toxins. This study evaluated antibacterial properties of Trachyspermum ammi Acetone, ethanol, methanol, cold water and hard water extracts of spice (Ajowan) seeds against four gram negative strains of pathogenic foodborne bacteria, E. coli O157:H7 ATCC 43888, ATCC 25922, ATCC 8739 and ATCC 43895 that cause infection and intoxication. E. coli ATCC 43888 was observed to be highly susceptible to all extracts of ajowan with absolute zones of inhibition in the range of $16 \mathrm{~mm}-23 \mathrm{~mm}$ in diameter. This study demonstrated that spice extracts have antimicrobial activity against food-borne bacterial species and should be considered as potential antibacterial agents for addition to ready meals. The spice contain high amount of secondary metabolites due to these metabolites they have high antimicrobial activity and it can be used as good bio- preserver and it can also use for medicinal purpose.
\end{abstract}

Keywords:

Antibacterial, Trachyspermum Ammi, Crude Extracts, Pathogenic Bacteria, Disk Diffusion.

\section{INTRODUCTION}

Plants have been a valuable source of natural products for a long period of time to maintain human health, especially with more intensive studies in the last decade for natural therapies (Gislene et al., 2000). Spices have been used for not only flavor and aroma of the foods but also to provide antimicrobial properties Natural preservatives are the chemical agents derived from plants that prevent the decomposition of products.${ }^{1}$ The mode of action of these natural preservatives is inhibition of microbial growth, oxidation and certain enzymatic reactions occurring in the food stuffs. Spices offer a promising alternative for food safety ${ }^{2}$. This study limelight naturally derived constituents of spice extracts contained high levels of phenolics and exhibited antibacterial activity against food borne pathogens. ${ }^{7}$ Some studies claim that the phenolic compounds present in spices and herbs might also play a major role in their antimicrobial effects. ${ }^{3}$ Food conservation for nutrition and shelf life can be obtained by controlling the growth of food borne pathogenic microorganisms and food spoilage. This could be achieved by suppressing one or more factors that are essential for microbial survival. ${ }^{4}$ Suppression might be possible by adding suitable chemical substances and by controlling physical factors for the growth of microbes. ${ }^{6}$ 


\section{MATERIAL AND METHODS}

Ajowan (Trachyspermum ammi) purchased from local market Indore, sterilized with $0.1 \% \mathrm{HgCl}_{2}$ and dried in hot air oven at $35-40^{\circ} \mathrm{C}$ for 2 to 3 days and are powdered using a blender. In order to obtain the spice extract about $100 \mathrm{~g}$ of spice soaked in $400 \mathrm{ml}$ of acetone, ethanol, methanol, cold water and hot water separately. The each suspension was stirred $150 \mathrm{rpm}$ at room temperature for $24 \mathrm{~h}$ after which it was filtered with the aid of Whatman filter No.1 under strict aseptic conditions. The extract was then rotary evaporated to dryness at $40^{\circ} \mathrm{C}$. The filtrate was collected in fresh sterilized glass tubes and stored at $4^{\circ} \mathrm{C}$ until use. The in vitro screening for antimicrobial study was carried out using selected bacterial strains. The antibacterial screening of the extracts were carried out by determining the zone of inhibition ( $\mathrm{mm}$ ) using disc diffusion method.

Tested Bacterial strains: Antibacterial activity of spice powder extracts was investigated against four gram negative strains of pathogenic foodborne bacteria E. coli O157:H7 ATCC 43888, ATCC 25922, ATCC 8739 and ATCC 43895 obtained from the Scientific Linkage Indore, India.

\section{METHOD}

The in vitro antibacterial activities of the test samples were carried out by disc diffusion method. ${ }^{7}$ Nutrient agar was used as culture media and the discs were placed aseptically over the bacterial culture on nutrient agar plates and incubated at $37^{\circ} \mathrm{C}$ for $24 \mathrm{hrs}$. After incubation for 24 hours the zone of inhibition around the discs measured by millimeter scale. Discs were impregnated with each treatment and control was assayed on duplicate agar medium plate. The diameter of zone of inhibition mean of four replicates as indicated by clear area which was devoid of growth of microbes was measured to determine antibacterial activity. Sterile blank paper discs impregnated with only acetone served as negative control each time. Standard erythromycins $(15 \mu \mathrm{g} /$ disc) used as positive control for comparison of the antibacterial activity.

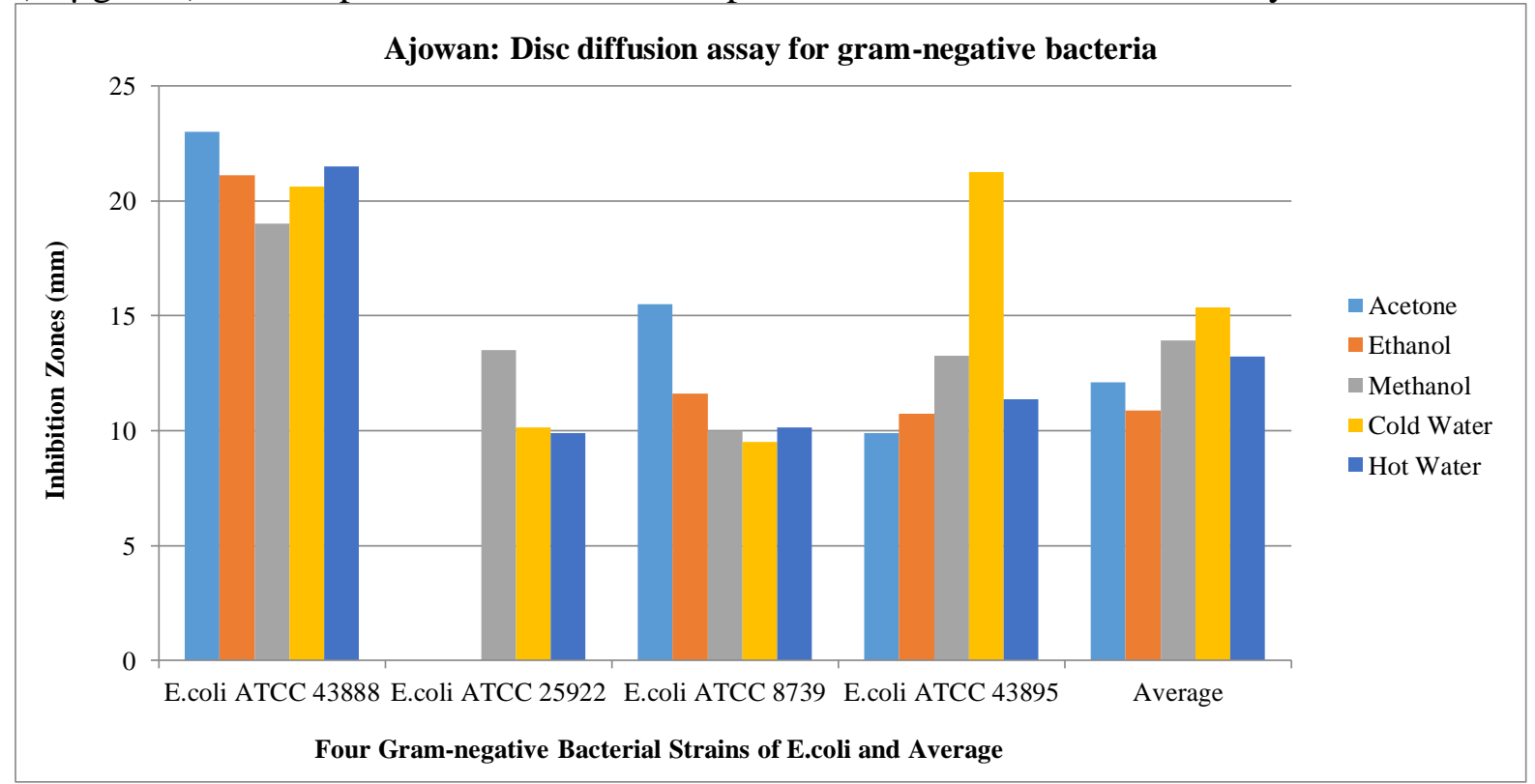

Average inhibition zone data of Gram-negative bacteria based on the disc diffusion assay for the various extracts of ajowan.

\section{RESULTS AND DISCUSSION}

E. coli ATCC 25922 was found to be the only bacteria they showed resistance when tested against three of the organic extracts (acetone and ethanol) of ajowan but exhibited inhibition zones of 
greater than $10 \mathrm{~mm}$ when tested against the organic extract, methanol (Figure).In the case of the aqueous extracts, both were found to have inhibitory effects of approximately $10 \mathrm{~mm}$ throughout the investigation. The results clearly indicated that for the remaining three gram-negative strains (E. coli ATCC 43888, E. coli ATCC 8739 and E. coli ATCC 43895) tested, all of the five extracts of ajowan exhibited profound inhibitory effects with inhibition zone sizes generally above $10 \mathrm{~mm}$. Comparison of the average inhibition zone sizes further substantiated that the extracts of ajowan produce inhibition amongst all of the Gram-negative bacteria (greater than $10 \mathrm{~mm}$ ) and that these extracts in fact prove to be highly effective antimicrobial agents for the purpose of the investigation. The order of effective for the extracts was as follows; cold water, methanol, hot water, acetone and ethanol. This study has evaluated the antimicrobial activity of ajowan, with emphasis on its application as effective antimicrobial agents, thereby enhancing the extent of ethno-botanical medicine and use in food.

E. coli O157:H7 ATCC 43888, ATCC 25922, ATCC 8739 and ATCC 43895 that cause infection and intoxication. E. coli ATCC 43888 was observed to be highly susceptible to all extracts of ajowan with absolute zones of inhibition in the range of $16 \mathrm{~mm}-23 \mathrm{~mm}$ in diameter. E. coli ATCC 25922 was resistant to the organic extracts acetone and ethanol but exhibited intermediate inhibition when tested against methanol and both aqueous extracts.

\section{CONCLUSION}

The type of solvent used to extract herbs and spices appeared to have a major impact on their antimicrobial activity. In this regard the use of spices and their volatile compounds as natural preservatives in food products and it may be an alternative to the use of chemical additives. Compounds extracted from Ajowan have a broad spectrum of antimicrobial activity which can be used as an alternative for antibiotics. Therefore, pharmacological test is necessary to isolate and characterize their active compounds. Moreover, these plants extract should be investigated in vivo to better understand their safety, efficacy and properties.

\section{REFERENCES}

1. Dorman H.J. and Deans S.G., Antimicrobial Agents from Plants: Antibacterial Activity of Plant Volatile Oils, J. Appl. Microbiology, 88, 308-16 (2000)

2. Arora D.S. and Kaur G.J., Antibacterial activity of some Indian medicinal plants, Journal of Natural Medicine, 61, 313-317 (2007)

3. Hara-Kudo Y., Kobayashi A., Sugita-Konishi Y. and Kondo K. Antibacterial activity of plants used in cooking for aroma and taste, J Food Protect, 67, 2820-2824 (2004)

4. Horace D.G., The safety of foods, Connecticut: AVI publishing Company (1982)

5. http://www.ijpbs.net/vol-3/issue-4/Pharma/8.pdf

6. http://www.ijcmas.com/vol-3-3/Bhawana\%20Pandey,\%20et\%20al.pdf

7. Brull S. and Coote P. Preservative agents in foods: mode of action and microbial resistance mechanisims, Int J Food Microbiol, l50, 1-17 (1999)

8. Bahttp://www.ijpbs.net/vol-3/issue-4/Pharma/8.pdfuer A.W., Kirby W.M., Sherris J.C. and Turck M., Antibiotic susceptibility testing by a standardized single disc method, American Journal of Clinical Pathology, 45, 493-496 (1966)

9. Zaika L.L. Spices and herbs: their antimicrobial activity and its determination, J Food Safety, 9, 97-118(1975) 